\title{
Phenolic acids and antioxidant properties of barley wholegrain and pearling fractions
}

\author{
Tamer H. Gamela,b and El-Sayed M. Abdel-Aal ${ }^{\mathrm{b} *}$ \\ a University of Alexandria, Faculty of Agriculture, \\ Department of Food Science and Technology, \\ El-Shatby 21545, Alexandria, Egypt \\ ${ }^{\mathrm{b}}$ Agriculture and Agri-Food Canada, Guelph Food Research Centre, \\ 93 Stone Road West, Guelph, ON, Canada, N1G 5C9 \\ e-mail: abdelaale@agr.gc.ca
}

\begin{abstract}
Demand for functional foods that offer therapeutic and disease-prevention properties is globally increasing. Barley presents an opportunity in this regard due to its high antioxidants and dietary fiber contents. Barley wholegrain and milling fractions were investigated in terms of phenolic acids composition, scavenging capacity against DPPH and ABTS radicals and inhibition of human LDL oxidation in vitro. Ferulic and $p$-coumaric were the primary phenolic acids in wholegrain and pearled fractions accounting for $43-97 \%$ and $2-55 \%$ of total phenolic acids, respectively. This wide range demonstrates significant differences among barley wholegrain or pearled products. Antioxidant capacities also varied significantly among barleys with the hulless cultivars tested exhibiting the greatest. The outer layers fraction showed higher scavenging capacity against ABTS and DPPH radicals and inhibitory effects toward LDL oxidation compared with the endosperm fractions. The results suggest that the outer layer and hull fractions would potentially provide promising sources of natural antioxidants.
\end{abstract}

Key words: barley, phenolic acids, LDL oxidation, DPPH, ABTS.

\section{Introduction}

Barley is one of the ancient cereal crops that currently have received increasing demands worldwide. It is gaining a renewed interest as a functional food ingredient due to its high content of bioactive compounds such as $\beta$-glucans (Pins and Kaur 2006), tocols (Peterson 1994), and phenolic compounds (Jadhav et al. 1998). Additionally, consumption of barley has been associated with lower total and serum cholesterol, improved postprandial glucose and insulin response (Kim et al. 2006, Wolever 2006, Yokoyama 2006, Wood 2007), and reduced heart disease (Behall and Hallfrisch 2006) and colon cancer (Dykes and Rooney 2007).

A wide range of phenolic antioxidant compounds has been found in barley such as benzoic and cinnamic acid derivatives, proanthocyanidins, flavonols, chalcones, flavones, flavanones, and amino phenolic compounds (McMurrough and Madigan, 1996, Goupy et al. 1999, Hernanz et al. 2001). They are present in free and bound form in cereals. Bound phenolics are ester-linked to cell-wall polymers in the outer layers of kernel. Ferulic acid and its dehydrodimer derivatives are the major phenolic compound in cereals present mainly in bound form (Manach et al. 2004, Madhujith et al. 2006, Choi et al. 2007, Kim et al. 2007). Phenolics and other antioxidants found in cereals may act as free radical scavengers (Ragaee et al. 2006) and/or reducing agents, chelating prooxidant metals and singlet oxygen quenchers (Zielinski 2002). Recently barley malt extract was found to prevent the reduction of antioxidant enzyme activities, to decrease levels

Manuscript received January 2012 


\section{AGRICULTURAL AND FOOD SCIENCE}

T. Gamel and E-S. Abdel-Aal (2012) 21: 118-131

of malondialdehyde and carbonyl in liver and brain, and to improve total antioxidant capability in the Dgalactose induced mouse aging model (Qingming et al. 2010). In addition, most of the natural antioxidants exhibit a wide range of biological effects including antibacterial, antiviral, anti-inflammatory, anti-allergic and anti-thrombotic effects, and may also be involved in vasodilatory actions (Cook and Sammon 1996).

Barley wholegrain and milling products exhibit large amount of $\beta$-glucan, dietary fiber, phenolic compounds and antioxidants. That would provide functional healthful ingredients for the development of a variety of functional foods with substantial health benefits. Thus the current study was designed to investigate phenolic acids composition and antioxidant capacity against 2,2-Diphenyl-1-Picrylhydrazyl (DPPH') and 2,2'-azino-di-[3-ethyl benzthiazoline sulphonate] (ABTS') radicals and inhibition of oxidation of human low-density lipoprotein (LDL) cholesterol of selected Canadian and Egyptian barley wholegrain flours, as well as four pearling fractions to identify potential barley materials for the functional food industry.

\section{Material and Methods}

\section{Barley wholegrain flours and pearling fractions}

The barley cultivars included in this study were three Canadian cultivars: AC Parkhill (2 rows, hulled, normal), Celebrity (6 rows, hulled, normal), and CDC Rattan (2 rows, hulless, waxy), and three Egyptian cultivars: Giza 127 (2 rows, hulled, normal), Giza 125 (6 rows, hulled, normal) and Giza 131 (2 rows, hulless, waxy). These cultivars were chosen based on their commercial value. The Canadian hulled barley cultivars were kindly provided by Cribit Seeds (West Montrose, ON, Canada) and the waxy hulless cultivar was obtained from University of Saskatchewan (Saskatoon, SK, Canada). Egyptian cultivars were obtained from the Agricultural Research Centre (Giza, Egypt). Barley cultivars were sequentially pearled on a Satake Abrasive Mill Model TM05 (Satake Corporation, Japan) to obtain four fractions: hull fraction (only for hulled cultivars), outer layers fraction (fraction 1), middle fraction (fraction 2) and inner or endosperm fraction (fraction 3) (Abdel-Aal and Gamel 2008). The outer layers fraction represented $13-15 \%$ of the kernel weight and consists mainly of pericarp (fruit coat) and testa (seed coat). The middle pearling fraction represented $12-15 \%$ of the kernel weight and would presumably contain parts of aluerone, testa and germ. The endosperm fraction represented the remaining $70-75 \%$ of the kernel weight, and it was mainly white endosperm. The hull fraction was almost pure hulls and represented about $10-12 \%$ of the hulled grain. The outer layer, middle and endosperm fractions, in addition to the wholegrain, were ground on a Cyclone Sample Mill (UDY Corp., Fort Collins, CO) equipped with a $1.0 \mathrm{~mm}$ screen. The hull fractions were ground on a Retsch Ball Mill (Model PM 100, Retsch GmbH, Haan, Germany) at 450 rpm for 4 min. The wholegrain and fraction flours were kept in a refrigerator $\left(4^{\circ} \mathrm{C}\right)$ for less than two weeks prior to analysis.

\section{Phenolic acids extraction and HPLC analysis}

Phenolic acids were extracted from barley wholegrain and pearling fractions as previously described (Abdel-Aal et al. 2001). Amount of $200 \mathrm{mg}$ of barley samples was weighed into a 250-ml centrifuging bottle and $15 \mathrm{ml}$ of $2 \mathrm{~N} \mathrm{NaOH}$ was added for alkaline extraction. The content was stirred at room temperature under nitrogen for $2 \mathrm{~h}$. Following extraction, the $\mathrm{pH}$ was adjusted to 2 with $6 \mathrm{~N} \mathrm{HCL}$, and $20 \mathrm{ml}$ of diethyl ether/ethyl acetate (1:1) was added. After shaking for $10 \mathrm{~min}$, the bottles were centrifuged at 14000 $\times \mathrm{g}$ for $10 \mathrm{~min}$ and the supernatant was gently transferred into a separator funnel and the water layer (bottom) was removed. The organic solvent extraction (top layer) was filtrated into a R-B flask through a layer of anhydrous $\mathrm{Na}_{2} \mathrm{SO}_{4}$. The organic extraction was repeated twice and all fractions of solvent were

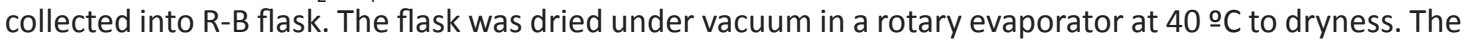
dried content was re-dissolved in $1 \mathrm{ml}$ of aqueous ethanol (95\%) and kept in a refrigerator for analysis. 


\section{AGRICULTURAL AND FOOD SCIENCE}

T. Gamel and E-S. Abdel-Aal (2012) 21: 118-131

Phenolic acids in barley extracts were separated and quantified by high performance liquid chromatography (HPLC) equipped with a G1311A quaternary pump, G1329A temperature-controlled injector, G1316A temperature-controlled column thermostat, G1322A degasser, G1315B photodiode array detector (PDA), and ChemStation Rev.B.02.01-SR2 data acquisition system with the capability of conducting isoabsorbance plot and 3D graphic analyses (Agilent Technologies Canada Inc., Mississauga, ON). A $25 \mathrm{~cm} \times 4.6 \mathrm{~mm}$ i.d., $5 \mu \mathrm{m}$ Supelcosil column LC 18 cat \# 58298 (Supelco, USA) was employed for separation. The column was maintained at $24 \pm 1{ }^{\circ} \mathrm{C}$ with the temperature-controlled column thermostat. A mixture of 12 authentic phenolic acids including gallic, protocatechuic, $p$-hydroxy-benzoic, gentisic, 3-hydroxy-benzoic, vanillic, caffeic, syringic, $p$-coumaric, ferulic, sinapic and o-coumaric acids was used for calibration, identification and quantification. For the separation of phenolic acids from barley extracts, $20 \mu l$ was injected and a gradient system was applied starting with a solvent ratio 100:0 of 6\% formic acid and acidified acetonitrile. The gradient was gradually changed over $35 \mathrm{~min}$ to $82: 18$ and then kept for the next $5 \mathrm{~min}$. After that 2 min were allowed to return to the starting conditions. The total run time was $42 \mathrm{~min}$. Since phenolic acids have various absorption maxima, they were monitored at 5 different channels: 230, 260, 275, 320 and $330 \mathrm{~nm}$ to enhance the accuracy of their quantification. In other words, protocatechuic, $p$-hydroxy-benzoic and vanillic acids were quantified at $260 \mathrm{~nm}$; syringic acid at $275 \mathrm{~nm}$; and caffeic, $p$-coumaric and ferulic acids at $320 \mathrm{~nm}$. The identity of phenloic acids were confirmed by isoabsorbance plot analysis. Typical HPLC chromatograms depicting the separation of phenolic acids from the standard mixture and selected barley fractions are presented in (Fig. 1). These chromatograms were constructed at $275 \mathrm{~nm}$ at which all the twelve phenolic acids showed reasonable response but gentisic acid. Gentisic acid appeared clearly at $330 \mathrm{~nm}$ but other phenolic acids showed very low response. All the phenolic acids and chemicals are HPLC grade and were obtained from Sigma-Aldrich.

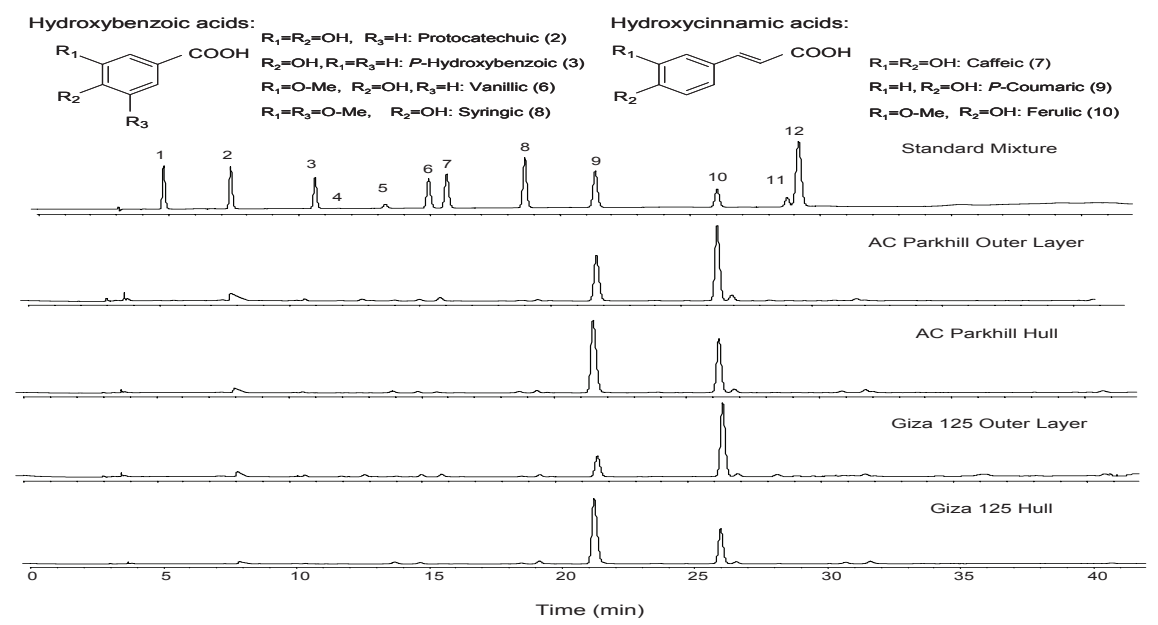

Fig. 1. Structures of phenolic acids found in the barley cultivars examined and HPLC chromatograms of the standard mixture and selected barley fractions. The phenolic acids were detected at $275 \mathrm{~nm}$ and separated on C18 reversed column in the following order: 1= gallic, $2=$ protocatechuic, $3=\mathrm{p}$ hydroxybenzoic, $\quad 4=$ gentisic, 5= 3-hydroxybenzoic, $6=$ vanillic, $7=$ caffeic, $8=$ syringic, $9=$ p-coumaric, $10=$ ferulic, $11=$ sinapic and $12=$ o-coumaric. 


\section{AGRICULTURAL AND FOOD SCIENCE}

T. Gamel and E-S. Abdel-Aal (2012) 21: 118-131

\section{Antioxidant properties}

Extracts for the determination of antioxidant capacities were prepared by weighing $1.0 \mathrm{~g}$ wholegrain or fraction flour in a $15-\mathrm{ml}$ centrifuge tube. A $10 \mathrm{ml}$ of $80 \%$ methanol was added and the mixture was immediately purged with a stream of nitrogen and thoroughly stirred on IKA shaker (VXR S1) for $30 \mathrm{~min}$, and then centrifuged at $3400 \mathrm{~g}$ for $20 \mathrm{~min}$. The extracts were transferred into dark color culture tubes, purged with a stream of nitrogen and then kept in a refrigerator until analysis.

\section{Scavenging capacity of DPPH radical}

Scavenging capacity of DPPH radical was carried out using the stable 2,2-diphenyl-1-picrylhydrazyl radical ( $\mathrm{DPPH}^{\circ}$ ) as previously described (Abdel-Aal and Rabalski 2008). The antioxidant reaction was initiated by transferring $1 \mathrm{ml}$ of barley methanol extract into a test tube containing $4 \mathrm{ml}$ of $80 \%$ methanol and $1 \mathrm{ml}$ of $1 \mathrm{mmol}$ freshly prepared DPPH${ }^{*}$ solution. The reaction mixture was monitored by reading absorbance at $517 \mathrm{~nm}$ for $30 \mathrm{~min}$ at $1 \mathrm{~min}$ intervals. A blank reagent was used to study stability of DPPH over the test time. The absorbance measured at $10 \mathrm{~min}$ was used for the calculation of $\mu \mathrm{mol} \mathrm{DPPH}^{\circ}$ scavenged by different fraction extracts. Butylated hydroxytoluene (BHT) was used as a synthetic antioxidant reference. The scavenging capacity of different barley fractions was calculated as $\mu$ mole DPPH g-1 sample.

\section{Scavenging capacity of ABTS radical cation}

The scavenging capacity against radical cation (2,2'-azino-di-[3-ethyl benzthiazoline sulphonate] (ABTS ${ }^{\bullet+}$ ) was measured using Randox Laboratories assay kit (San Francisco, CA). Trolox (6-hydroxy 2,5,7,8-tetramethylchroman-2-carboxylic acid) provided in the kit was used as an antioxidant standard and for the calculation of scavenging capacity of barley methanol extracts as trolox equivalent. The scavenging capacity of barley fractions was calculated as $\mu \mathrm{mol}$ of quenched $A B T S \mathrm{~g}^{-1}$ sample and as Trolox equivalent antioxidant capacity or TEAC (Arts et al. 2004).

\section{Inhibition of copper-induced human LDL oxidation}

The inhibition capacity of barley methanol extracts against oxidation of copper-induced human LDL cholesterol was based on the method modified by Abdel-Aal and Gamel (2008). Human LDL cholesterol ( $5 \mathrm{mg}$ protein $\mathrm{ml}^{-1}$ in $0.05 \mathrm{~mol}$ Tris- $\mathrm{HCl}, 0.15 \mathrm{~mol} \mathrm{NaCl}$ and $0.3 \mathrm{mmol}$ EDTA at $\mathrm{pH} 7.4$ ) was dialyzed against $10 \mathrm{mmol}$ phosphate buffer saline or PBS ( $\mathrm{pH} 7.4,0.15 \mathrm{~mol} \mathrm{NaCl}$ ) for $24 \mathrm{~h}$ under nitrogen at $4^{\circ} \mathrm{C}$, with buffer change once after $10 \mathrm{~h}$. The EDTA-free LDL was subsequently diluted with PBS to obtain a standard protein concentration of $250 \mu \mathrm{g} \mathrm{ml}^{-1}$. The LDL solution (800 $\mu \mathrm{l}$ ) was mixed with $100 \mu \mathrm{l}$ of diluted sample extract ( $30 \mu \mathrm{l}$ extract and $70 \mu \mathrm{l} 80 \%$ aqueous methanol) in a 4-ml test tube. Oxidation of LDL was initiated by adding $200 \mu \mathrm{l}$ of $50 \mu \mathrm{mol}$ cupric sulphate solution. The mixture was incubated at $37^{\circ} \mathrm{C}$ and the formation of conjugated diene (CD) was measured spectrophotometrically at $234 \mathrm{~nm}$ after $8 \mathrm{~h}$, at which the oxidation reaction reaches its peak (Abdel-Aal and Gamel 2008). Butylated hydroxytoluene (BHT) at concentration $75 \mathrm{ppm}$ was included as a reference antioxidant. For the measurement of conjugated dienes, $100 \mu$ l of oxidized LDL mixture was added to $1200 \mu \mathrm{l}$ iso-propanol in a 1.5-ml eppendorf tube. After vigorous shaking for $2 \mathrm{~min}$, the sample was centrifuged at $6000 \mathrm{~g}$ for $5 \mathrm{~min}$ and the supernatant was read on a spectrophotometer (Cary 3C, Varian Australia Pty Ltd.) at $234 \mathrm{~nm}$. The amount of conjugated dienes formed was calculated using the molar extinction coefficient $29500 \mathrm{~mol} \mathrm{l}^{-1} \mathrm{~cm}^{-1}$ (Esterbauer et al. 1989). The effect of antioxidants on inhibition of diene formation was calculated as the difference between the 


\section{AGRICULTURAL AND FOOD SCIENCE}

T. Gamel and E-S. Abdel-Aal (2012) 21: 118-131

amount of formed diene in the control sample (antioxidant free) and the amount of formed diene in the presence of antioxidant barley extracts.

\section{Statistical analysis}

The wholegrain and flour fractions were randomized and all analyses were run in three replicates. Twoway ANOVA and Duncan's multiple range tests were run to determine significant differences in phenolic acids and antioxidant properties between barley wholegrain flours and fractions. Pearson correlation analysis was carried out to identify relationships between phenolic acids and antioxidant properties. All statistical analyses were performed using Minitab software (version 12, Minitab inc., State College, PA). Differences were considered to be significant when $p<0.05$. The data were reported as means of three replicates \pm standard deviation (SD).

\section{Results and Discussion}

\section{Composition of phenolic acids in barley wholegrain}

Phenolic acids are plant metabolites widely spread throughout the plant kingdom. Recent interest in phenolic acids stems from their potential protective role in human health. Several phenolic acids including ferulic, $p$-coumaric, gallic, vanillic, caffeic, syringic, protocatechuic, chlorogenic, and $p$-hydroxy-benzoic acids have been reported to accumulate in barley kernel and distributed among the grain (MacGregor and Fincher 1993, Manach et al. 2004, Dykes and Rooney 2007). In the current study, selected Canadian and Egyptian barley cultivars exhibiting various compositions were investigated in terms of phenolic acids composition. Seven phenolic acids, protocatechuic, $p$-hydroxy-benzoic, vanillic, caffeic, syringic, $p$-coumaric and ferulic, were separated and identified in the barley grains and fractions analyzed (Fig. 1). In general, barley contained good level of phenolic acids but significant differences were observed among the barley wholegrain flours tested (Table 1). Wholegrain flours obtained from the Egyptian cultivars were found to exhibit significantly higher amounts of phenolic acids compared with the Canadian cultivars. In particular the Egyptian cultivars Giza 125 and Giza 127 seem to have the highest concentration of phenolic acids. They also exhibited high levels of ferulic and $p$-coumaric acids compared with the other cultivars. The Egyptian barleys were grown in relatively high temperature and low rainfall compared to the Canadian ones. It has been reported that when plant faced conditions with excess oxidation caused by UV irradiation and chemicals, or pathogen attack and other kinds of stress, it starts produce more secondary metabolite molecules such as phenolic acids as a self-mechanism for scavenging of free radicals and anti-stress protection (Duthie et al. 2000, Manach et al. 2004). This could be the case with the Egyptian cultivars that were sowed in relatively harsh environmental conditions especially drought that occurs by high temperature effects. Nogués et al. (1998) reported that flavonoids and anthocyanins in pea (Pisum sativum L. cv 'Meteor') significantly and synergistically increased as a function of both drought and UV-B radiation. Contrarily cold temperatures can destroy or block the metabolic pathway of certain compounds. Christie et al. (1994) observed that very cold temperatures destroy the biosynthetic capability of anthocyanin in maize. In addition, genotype and environment have also been found to significantly influence total phenol content, antioxidant capacity and phenolic acids in hard spring wheat (Mpofu et al. 2006). 


\section{AGRICULTURAL AND FOOD SCIENCE}

T. Gamel and E-S. Abdel-Aal (2012) 21: 118-131

Table 1.Composition of phenolic acids ( $\mathrm{mg} \mathrm{g}^{-1}$, dry matter) of selected wholegrain barley cultivars a .

\begin{tabular}{|c|c|c|c|c|c|c|c|c|}
\hline $\begin{array}{l}\text { Barley } \\
\text { wholegrain }\end{array}$ & $\begin{array}{c}\text { Protocat- } \\
\text { echuic }\end{array}$ & $\begin{array}{l}p \text {-Hydroxy- } \\
\text { benzoic }\end{array}$ & Vanillic & Caffeic & Syringic & $p$-Coumaric & Ferulic & Total \\
\hline \multicolumn{9}{|c|}{2 rows, hulled normal cultivars } \\
\hline AC Parkhill & nd & $\begin{array}{l}2.4 \mathrm{ab} \\
(0.9)^{\mathrm{b}}\end{array}$ & $\begin{array}{c}6.10 \mathrm{ab} \\
(2.0)\end{array}$ & nd & nd & $\begin{array}{l}55.9 \mathrm{bc} \\
(18.9)\end{array}$ & $\begin{array}{l}231.5 \mathrm{c} \\
(78.2)\end{array}$ & $295.9 \mathrm{c}$ \\
\hline Giza 127 & $\begin{array}{l}2.2 \mathrm{a} \\
(0.4)\end{array}$ & $\begin{array}{l}4.4 \mathrm{a} \\
(0.8)\end{array}$ & $\begin{array}{l}12.3 \mathrm{a} \\
(2.3)\end{array}$ & $\begin{array}{l}6.3 \mathrm{a} \\
(1.2)\end{array}$ & $\begin{array}{l}1.8 \mathrm{a} \\
(0.3)\end{array}$ & $\begin{array}{l}90.7 \mathrm{a} \\
(16.8)\end{array}$ & $\begin{array}{l}\text { 421.0ab } \\
(78.2)\end{array}$ & $538.7 \mathrm{a}$ \\
\hline \multicolumn{9}{|c|}{6 rows, hulled normal cultivars } \\
\hline Celebrity & nd & $\begin{array}{l}1.0 \mathrm{~b} \\
(0.6)\end{array}$ & $\begin{array}{l}4.2 \mathrm{ab} \\
(2.5)\end{array}$ & nd & $\begin{array}{l}1.1 \mathrm{ab} \\
(0.6)\end{array}$ & $\begin{array}{l}40.8 b c \\
(23.8)\end{array}$ & $\begin{array}{l}124.1 \mathrm{~d} \\
(72.5)\end{array}$ & $171.2 \mathrm{~d}$ \\
\hline Giza 125 & $\begin{array}{l}2.1 \mathrm{a} \\
(0.4)\end{array}$ & $\begin{array}{c}3.6 \mathrm{ab} \\
(0.6)\end{array}$ & $\begin{array}{l}10.1 \mathrm{a} \\
(1.8)\end{array}$ & $\begin{array}{l}2.5 b \\
(0.5)\end{array}$ & $\begin{array}{l}0.7 \mathrm{~b} \\
(0.1)\end{array}$ & $\begin{array}{l}69.0 \mathrm{ab} \\
(12.5)\end{array}$ & $\begin{array}{l}466.0 \mathrm{a} \\
(84.1)\end{array}$ & $554.0 \mathrm{a}$ \\
\hline \multicolumn{9}{|c|}{2 rows, hulless waxy cultivars } \\
\hline CDC Rattan & $\begin{array}{l}2.5 \mathrm{a} \\
(0.7)\end{array}$ & $\begin{array}{l}1.9 \mathrm{ab} \\
(0.5)\end{array}$ & $\begin{array}{c}6.7 \mathrm{ab} \\
(1.8)\end{array}$ & $\begin{array}{l}3.0 \mathrm{~b} \\
(0.8)\end{array}$ & nd & $\begin{array}{l}6.5 \mathrm{~d} \\
(1.7)\end{array}$ & $\begin{array}{l}360.2 \mathrm{~b} \\
(94.5)\end{array}$ & $380.8 \mathrm{bc}$ \\
\hline Giza 131 & $\begin{array}{l}1.5 \mathrm{a} \\
(0.3)\end{array}$ & $\begin{array}{l}1.3 \mathrm{~b} \\
(0.3)\end{array}$ & $\begin{array}{l}2.3 \mathrm{~b} \\
(0.5)\end{array}$ & $\begin{array}{l}2.2 \mathrm{~b} \\
(0.5)\end{array}$ & nd & $\begin{array}{l}34.0 \mathrm{c} \\
(7.7)\end{array}$ & $\begin{array}{c}403.0 \mathrm{ab} \\
(90.7)\end{array}$ & $444.3 \mathrm{ab}$ \\
\hline
\end{tabular}

${ }^{a}$ Means within a column followed by the same letter are not significantly different at $p<0.05, \mathrm{n}=3$.

${ }^{b}$ Values in brackets are percentage of each phenolic acid to the total phenolic acids. nd $=$ not detected.

\section{Composition of phenolic acids in barley grain fractions}

Ferulic acid was found to constitute about $73-95 \%$ of the total phenolic acids in the wholegrain of the six cultivars examined, whereas $p$-coumaric acid comes second accounting for $2-24 \%$ and showing a wide range among barley cultivars and fractions. These two compounds have been previously reported as the dominant phenolic acids in barley (Hernanz et al. 2001, Szwajgier et al. 2005, Du et al. 2009) and wheat (Klepacka and Fornal 2006, Mussatto et al. 2007). Protocatechuic and caffeic acids were found in the Egyptian hulled cultivars, but they were missing in the Canadian hulled ones. On the other hand, the Canadian hulless cultivar, CDC Rattan, contained protocatechuic and caffeic acids. The latter cultivar was superior in phenolic acids content among the Canadian barleys, while on the contrary, the Egyptian hulless cultivar, Giza 131, had the lowest phenolics content among the Egyptian cultivars. Both hulless cultivars (CDC Rattan and Giza 131) were found to be deficient in syringic acid among the studied phenolics.

Several studies have shown that phenolic acids are the major phytochemicals found in barley and are mainly concentrated in the outer layers of the kernel with a low amount in the endosperm (Maillard and Berset 1995, Madhujith et al. 2006, Choi et al. 2007). In this study, distribution of phenolic acids in barley kernel parts (hulls, outer layers, middle pearling and endosperm) was assessed in the six selected barleys. The type and level of phenolic acids were differed between the milling fractions being the highest in the hull and outer layer fractions and lowest in the endosperm fractions (Table 2). The hull fractions had the highest total phenolic acids content among all the fractions followed by fraction 1 (outer layers), fraction 2 (middle pearling) and finally fraction 3 (endosperm). Similar outcome was reported for wheat grains, where the total phenolics were concentrated in the first and second outer pearling fractions (Beta et al. 2005). The husk fraction of Thai rice also showed greater phenolic acids concentrations than the other fractions (Butsat and Siriamornpun 2010).

As expected ferulic acid was found to be mainly concentrated in the outer layers of the six selected barley cultivars (Table 2) as previously reported (MacGregor and Fincher 1993, Manach et al. 2004, Kim et al. 2007). Ferulic acid is a potent antioxidant having a capability to inhibit lipid peroxidation in microsomal membranes and to protect marine fibroblasts (Trombino et al. 2004). It was also found to powerfully scavenge alkylperoxyl radicals in the $\beta$-carotene-linoleic acid emulsion system (Terpinc and Abramovič 2010). The hull fraction was exceptionally high in $p$-coumaric, ferulic and syringic acids and may offer an 


\section{AGRICULTURAL AND FOOD SCIENCE}

T. Gamel and E-S. Abdel-Aal (2012) 21: 118-131

excellent source of phenolic acids as natural antioxidants. However, the bioavailability of phenolic acids in this fraction should be taken into consideration, and further research is needed to assess its suitability as natural antioxidants. The content of ferulic acid in the endosperm fraction of the six cultivars examined was relatively low compared with the other milling fractions. In general the endosperm fraction (fraction 3) was also deficient in other phenolic acids such as protocatechuic and syringic in all the studied cultivars.

Table 2.Phenolic acids distribution in different pearling fractions of barley cultivars ( $\mu \mathrm{g} \mathrm{g}^{-1}$, dry matter)

\begin{tabular}{|c|c|c|c|c|c|c|c|c|}
\hline Barley Fractions & $\begin{array}{l}\text { Protocat- } \\
\text { echuic }\end{array}$ & $\begin{array}{l}p \text {-hydroxy } \\
\text { benzoic }\end{array}$ & Vanillic & Caffeic & Syringic & $p$-Coumaric & Ferulic & Total \\
\hline \multicolumn{9}{|c|}{2 rows, hulled normal cultivars } \\
\hline \multicolumn{9}{|l|}{ AC Parkhill } \\
\hline Fraction 1 & nd & $9.1 \mathrm{~b} \quad(1.0)^{\mathrm{b}}$ & $15.0 \mathrm{~cd}(1.7)$ & $26.1 \mathrm{~b}(26.1)$ & $5.7 c(0.6)$ & $221.7 c(24.6)$ & $623.6 \mathrm{bc}(69.2)$ & $901.2 \mathrm{c}$ \\
\hline Fraction 2 & nd & $10.0 \mathrm{~b}(3.8)$ & $14.4 \mathrm{~cd}(5.6)$ & 6.6de (2.6) & nd & $72.0 \mathrm{~cd}(28.0)$ & $154.3 \mathrm{ef}(60)$ & $257.3 \mathrm{cde}$ \\
\hline Fraction 3 & nd & 2.2de (1.7) & $1.5 f(1.2)$ & nd & nd & $16.5 \mathrm{~d}(12.8)$ & $108.5 \mathrm{ef}(84.3)$ & $128.7 \mathrm{de}$ \\
\hline Hull & $4.1 \mathrm{bc}(0.2)$ & $9.7 \mathrm{~b} \quad(0.5)$ & $19.5 b c(1.1)$ & $16.3 \mathrm{bc}(0.9)$ & $16.3 a b(0.9)$ & $805.2 b(45.5)$ & 897.5ab (50.7) & 1768.6ab \\
\hline \multicolumn{9}{|l|}{$\underline{\text { Giza } 127}$} \\
\hline Fraction 1 & $2.7 c d(0.3)$ & $7.1 \mathrm{bc}(0.9)$ & $17.6 \mathrm{~cd}(2.2)$ & $7.2 \mathrm{de}(0.9)$ & $4.1 c(0.5)$ & $157.0 \mathrm{~cd}(19.3)$ & $616.1 \mathrm{bc}(75.9)$ & $811.8 \mathrm{c}$ \\
\hline Fraction 2 & nd & 0.7 e $(0.4)$ & $2.0 f(1.3)$ & 2.0ef (1.3) & $0.8 \mathrm{c}(0.5)$ & $12.5 d(8.0)$ & $138.5 \mathrm{ef}(88.5)$ & $156.5 \mathrm{de}$ \\
\hline Fraction 3 & nd & nd & nd & $0.88 f(2.1)$ & nd & $10.7 d(25.9)$ & $29.8 f(72.0)$ & $41.38 \mathrm{e}$ \\
\hline Hull & $3.6 \mathrm{bc}(0.2)$ & 17.9a (0.9) & $40.5 a(2.1)$ & 5.5 de $(0.3)$ & 21.7a (1.1) & $938.3 b(48.5)$ & $905.7 \mathrm{ab}(46.8)$ & 1933.2ab \\
\hline \multicolumn{9}{|c|}{6 rows, hulled normal cultivars } \\
\hline \multicolumn{9}{|l|}{ Celebrity } \\
\hline Fraction 1 & $3.3 \mathrm{bc}(0.6)$ & 2.6de (0.5) & 10.3de (1.8) & $24.0 \mathrm{bc}(4.3)$ & $1.3 c(0.2)$ & $91.6 \mathrm{~cd}(16.4)$ & 424.0cde (76.1) & $557.1 \mathrm{~cd}$ \\
\hline Fraction 2 & $1.8 \mathrm{~d}(0.3)$ & 2.1de $(0.3)$ & 8.3ef (1.3) & $25.7 \mathrm{~b}(4.0)$ & $0.9 c(0.1)$ & $88.7 \mathrm{~cd}(13.7)$ & $518.1 \mathrm{~cd}(80.3)$ & $645.6 \mathrm{~cd}$ \\
\hline Fraction 3 & nd & $0.2 \mathrm{e} \quad(0.2)$ & $1.2 f(1.2)$ & nd & nd & $16.8 \mathrm{~d}(17.2)$ & $79.5 f(81.4)$ & $97.7 \mathrm{de}$ \\
\hline Hull & $4.3 b(0.2)$ & $7.0 \mathrm{bc} \quad(0.3)$ & $24.5 \mathrm{~b}(1.0)$ & $10.6 \mathrm{cde}(0.5)$ & $15.7 \mathrm{~b}(0.7)$ & 1271.9a (54.1) & 1018.7a (43.3) & $2352.7 a$ \\
\hline \multicolumn{9}{|l|}{ Giza 125} \\
\hline Fraction 1 & $2.5 \mathrm{~cd}(0.3)$ & $4.8 \mathrm{~cd}(0.6)$ & $18.6 \mathrm{bc}(2.5)$ & $19.9 \mathrm{bc}(2.7)$ & $2.5 \mathrm{c}(0.3)$ & $98.6 \mathrm{~cd}(13.2)$ & $601.3 b c(80.4)$ & $748.2 \mathrm{c}$ \\
\hline Fraction 2 & $1.6 \mathrm{~d}(0.6)$ & $3.7 \mathrm{cde}(1.3)$ & 8.1ef (2.9) & 3.6de (1.3) & nd & $22.6 \mathrm{~d}(8.2)$ & 236.6def (85.7) & $276.2 \mathrm{cde}$ \\
\hline Fraction 3 & nd & nd & nd & nd & nd & $2.6 \mathrm{~d}(9.2)$ & $25.8 f(90.8)$ & $28.4 \mathrm{e}$ \\
\hline Hull & $2.1 \mathrm{~cd}(0.1)$ & $6.3 c(0.4)$ & $25.1 \mathrm{~b}(1.7)$ & $1.3 e f(0.1)$ & $12.6 \mathrm{~b}(0.8)$ & $786.0 \mathrm{~b}(51.9)$ & $681.4 \mathrm{bc}(45.0)$ & $1514.8 b$ \\
\hline \multicolumn{9}{|c|}{2 rows, hulless waxy cultivars } \\
\hline \multicolumn{9}{|l|}{ CDC Rattan } \\
\hline Fraction 1 & $6.5 a(0.7)$ & $6.6 \mathrm{c} \quad(0.7)$ & $20.5 b c(2.1)$ & $54.6 a(5.6)$ & $2.7 c(0.3)$ & $14.8 \mathrm{~d}(1.5)$ & $867.5 \mathrm{ab}(89.1)$ & $973.2 \mathrm{bc}$ \\
\hline Fraction 2 & $2.7 \mathrm{bc}(0.5)$ & $3.85 \mathrm{cde}(0.7)$ & 9.5 de (1.7) & $13.2 \mathrm{~cd}(2.4)$ & nd & $7.8 \mathrm{~d}(1.4)$ & $511.5 \mathrm{~cd}(93.3)$ & $548.6 \mathrm{cde}$ \\
\hline Fraction 3 & nd & nd & nd & nd & nd & $1.2 \mathrm{~d}(7.5)$ & $14.7 f(92.5)$ & $15.9 \mathrm{e}$ \\
\hline \multicolumn{9}{|l|}{$\underline{\text { Giza } 131}$} \\
\hline Fraction 1 & $3.3 \mathrm{bc}(0.5)$ & $3.5 \mathrm{cde}(0.5)$ & $15.0 \mathrm{~cd}(2.2)$ & $19.6 \mathrm{bc}(2.9)$ & $2.6 c(0.4)$ & $55.9 \mathrm{~cd}(8.5)$ & $567.1 \mathrm{~cd}(85.0)$ & $667 \mathrm{~cd}$ \\
\hline Fraction 2 & $2.4 \mathrm{~cd}(0.5)$ & $4.4 c(1.0)$ & 8.4ef (1.9) & $14.3 \mathrm{~cd}(3.2)$ & $1.2 \mathrm{c}(0.3)$ & $28.8 \mathrm{~d}(6.5)$ & $383.7 \mathrm{cde}(86.6)$ & $443.2 \mathrm{~cd}$ \\
\hline Fraction 3 & nd & $0.6 e(0.5)$ & $5.4 \mathrm{ef}(4.7)$ & 3.6de (3.1) & nd & $6.8 \mathrm{~d}(5.9)$ & 99.7ef (85.9) & 116.1de \\
\hline
\end{tabular}

${ }^{\text {a }}$ Means within a column followed by the same letter are not significantly different at $p<0.05, \mathrm{n}=3$.

${ }^{\text {b}}$ Values in brackets are percentage of each phenolic acid to the total phenolic acids.

Fraction $1=$ outer layers (mainly pericarp and testa), fraction $2=$ middle pearling (parts of aluerone, testa and germ), fraction $3=$ inner fraction (mainly white endosperm). nd = not detected. 


\section{AGRICULTURAL AND FOOD SCIENCE}

T. Gamel and E-S. Abdel-Aal (2012) 21: 118-131

\section{Antioxidant Properties}

\section{Scavenging capacity against DPPH and ABTS}

It has been accepted that dietary antioxidants may combat reactive oxygen species and free radicals generated during cellular metabolism or peroxidation of lipids and other biological molecules resulting in reducing the risk of chronic diseases. In the current study scavenging capacity of free radicals and inhibitory effects of lipid oxidation of barley cultivars and milling fractions were evaluated. Scavenging capacity against DPPH (Fig. 2) and ABTS (Table 3) radicals varied significantly between milling fractions and barley wholegrain flours. The antioxidant capacity of the outer layers and hull fractions was considerably high, indicating their potential as natural antioxidant sources. This capability would be supported by high contents of phenolic acids in the cultivars. The DPPH scavenging capacity of the outer layers and hull fractions were in the range of 42.6 -64.0 and 11.4-31.5 $\mu$ mole $\mathrm{g}^{-1} \mathrm{dry}$ sample, respectively. The DPPH scavenging capacity of the outer layer fractions was comparable with the $50.6 \mu$ mole for $75 \mathrm{ppm} \mathrm{BHT}$. The ABTS scavenging capacity also showed a broad spectrum ranging from 0.237 (AC Parkhill fraction 3 ) to 0.482 (Celebrity fraction 1). The wholegrain flour of both Canadian and Egyptian hulless cultivars (CDC Rattan and Giza 131) exhibited the highest scavenging capacity for both types of free radicals. Similar antioxidant capacity against ABTS was achieved by the outer layers and hull fractions of all the cultivars except for AC Parkhill after $10 \mathrm{~min}$ (Table 3). The results show that methanolic extracts of Egyptian cultivars exhibit greater free radicals scavenging capacity than those of the Canadian ones. The outer layer and hull fractions of all the cultivars had high Trolox equivalent antioxidant capacity (TEAC) that was approximately similar to that obtained by $75 \mathrm{ppm}$ BHT after 10 and 30 min of oxidation (Table 3). It was previously reported that the antioxidant capacity of wheat phenolics extract is largely related to the 5 and $10 \%$ pearling fractions and was correlated with the high phenolics content in these fractions (Beta et al. 2005).

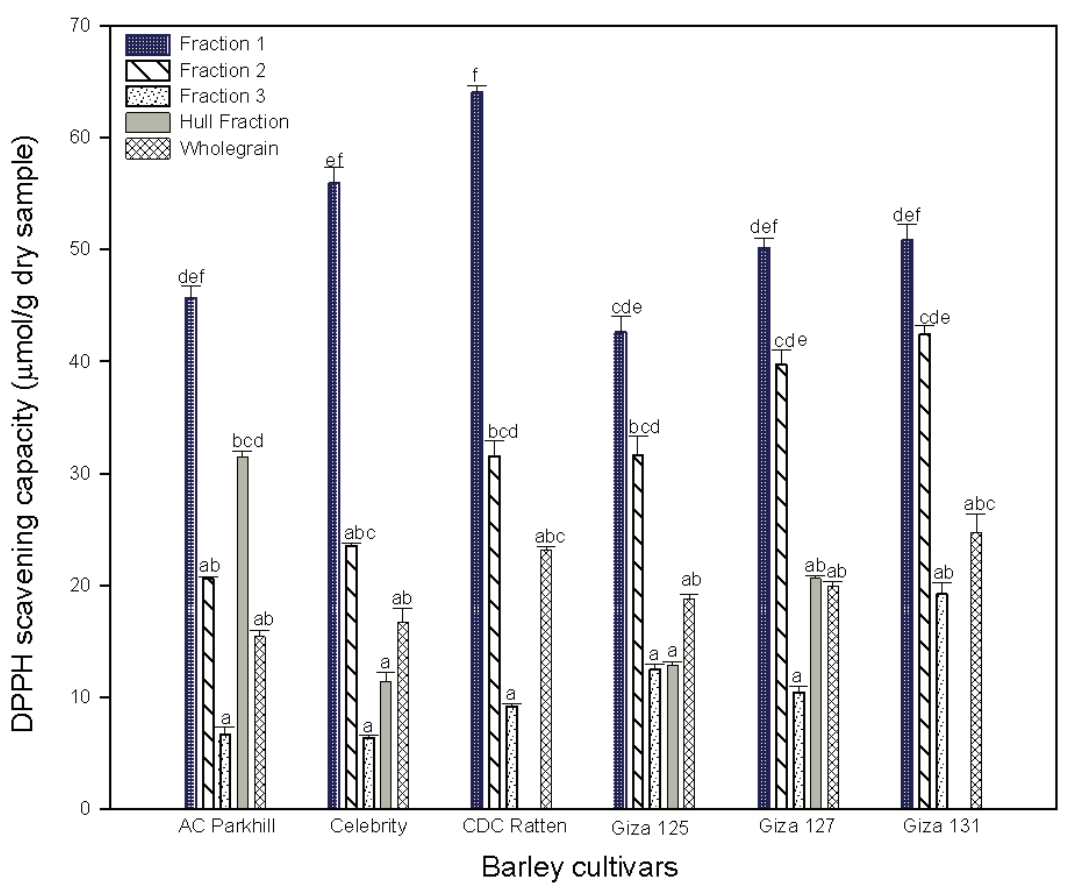

Fig. 2. Scavenging capacity of DPPH free radical of barley cultivars and fractions. Fraction $1=$ outer layers (mainly pericarp and testa), fraction $2=$ middle pearling (parts of aluerone, testa and germ), fraction $3=$ inner fraction (mainly white endosperm). Error bars represent standard deviation values. Different letters indicate significant differences between cultivars and fractions at $p<0.05$. 


\section{AGRICULTURAL AND FOOD SCIENCE}

T. Gamel and E-S. Abdel-Aal (2012) 21: 118-131

Table 3. Scavenging capacity of ABTS radical cation and teac of barley cultivars and pearling fractions ${ }^{a}$.

\begin{tabular}{|c|c|c|c|c|c|c|}
\hline \multirow{2}{*}{ Samples } & \multicolumn{3}{|c|}{$\mu \mathrm{mol}$ of scavenged ABTS $\mathrm{g}^{-1}$ dry sample } & \multicolumn{3}{|c|}{ TEAC $^{b}$} \\
\hline & $6 \mathrm{~min}$ & $10 \mathrm{~min}$ & $30 \mathrm{~min}$ & $6 \mathrm{~min}$ & $10 \min$ & $30 \mathrm{~min}$ \\
\hline BHT (75 ppm) & $0.58 a b$ & $0.57 a$ & $0.512 a$ & 1.4 & 1.8 & 3.8 \\
\hline \multicolumn{7}{|c|}{2 rows, hulled normal cultivars } \\
\hline \multicolumn{7}{|l|}{$\underline{\text { AC Parkhill }}$} \\
\hline Fraction 2 & $0.532 \mathrm{~cd}$ & $0.483 b c$ & $0.341 \mathrm{de}$ & 1.3 & 1.5 & 2.5 \\
\hline Fraction 3 & $0.461 f$ & $0.405 \mathrm{e}$ & $0.237 f$ & 1.1 & 1.3 & 1.8 \\
\hline Wholegrain & 0.490 ef & $0.436 \mathrm{de}$ & $0.281 \mathrm{ef}$ & 1.2 & 1.4 & 2.1 \\
\hline Hull & $0.573 a b$ & $0.544 a$ & $0.409 \mathrm{~cd}$ & 1.4 & 1.7 & 3.0 \\
\hline \multicolumn{7}{|l|}{ Giza 127} \\
\hline Wholegrain & $0.511 \mathrm{de}$ & $0.463 c d$ & $0.337 \mathrm{de}$ & 1.2 & 1.4 & 2.3 \\
\hline Hull & $0.532 \mathrm{~cd}$ & $0.488 \mathrm{bcd}$ & $0.355 \mathrm{de}$ & 1.4 & 1.7 & 3.3 \\
\hline \multicolumn{7}{|c|}{6 rows, hulled normal cultivars } \\
\hline Fraction 1 & $0.594 a$ & $0.578 a$ & $0.482 \mathrm{ab}$ & 1.4 & 1.8 & 3.5 \\
\hline Fraction 2 & $0.519 \mathrm{de}$ & $0.469 c d$ & $0.326 \mathrm{e}$ & 1.3 & 1.6 & 2.8 \\
\hline Fraction 3 & $0.456 f$ & $0.400 \mathrm{e}$ & $0.237 f$ & 1.2 & 1.3 & 1.9 \\
\hline Wholegrain & $0.479 \mathrm{ef}$ & $0.424 \mathrm{de}$ & $0.264 f$ & 1.2 & 1.4 & 2.2 \\
\hline Hull & $0.559 a b c$ & $0.515 a b$ & $0.364 d$ & 1.5 & 1.8 & 3.6 \\
\hline \multicolumn{7}{|c|}{2 rows, hulless waxy cultivars } \\
\hline \multicolumn{7}{|l|}{ CDC Rattan } \\
\hline Fraction 1 & $0.584 a b$ & $0.565 a$ & $0.473 a b c$ & 1.4 & 1.8 & 3.5 \\
\hline Fraction 2 & $0.549 \mathrm{bcd}$ & $0.503 b c$ & $0.379 d$ & 1.3 & 1.6 & 2.8 \\
\hline Fraction 3 & $0.476 \mathrm{ef}$ & $0.416 \mathrm{e}$ & $0.251 f$ & 1.2 & 1.3 & 1.9 \\
\hline Wholegrain & $0.489 \mathrm{ef}$ & $0.436 \mathrm{de}$ & $0.300 \mathrm{ef}$ & 1.2 & 1.4 & 2.2 \\
\hline \multicolumn{7}{|l|}{ Giza 131} \\
\hline$\overline{\text { Fraction } 1}$ & $0.587 a$ & $0.566 a$ & $0.455 a b c$ & 1.4 & 1.8 & 3.4 \\
\hline Fraction 2 & $0.561 \mathrm{abc}$ & $0.524 a b$ & $0.402 c d$ & 1.4 & 1.6 & 3.0 \\
\hline Fraction 3 & $0.504 \mathrm{e}$ & $0.454 \mathrm{de}$ & $0.302 \mathrm{ef}$ & 1.2 & 1.4 & 2.2 \\
\hline Wholegrain & $0.504 \mathrm{e}$ & $0.450 \mathrm{de}$ & $0.308 \mathrm{ef}$ & 1.2 & 1.4 & 2.3 \\
\hline
\end{tabular}

${ }^{\mathrm{a}}$ Means within a column followed by the same letter are not significantly different at $p<0.05, \mathrm{n}=3$.

${ }^{b}$ Trolox Equivalent Antioxidant Capacity, TEAC of Trolox $(8.86 \mu \mathrm{g}$ or $1.77 \mathrm{mmol})=1$.

Fraction $1=$ outer layers (mainly pericarp and testa), fraction $2=$ middle pearling (parts of aluerone, testa and germ), fraction $3=$ inner fraction (mainly white endosperm). 


\section{AGRICULTURAL AND FOOD SCIENCE}

T. Gamel and E-S. Abdel-Aal (2012) 21: 118-131

\section{Inhibition of LDL cholesterol oxidation}

High level of plasma low-density lipoprotein (LDL) cholesterol and its oxidation products are important factors in the development of atherosclerosis and heart disease (Frei 1995, Jialal and Devaraj 1996). Oxidation of LDL cholesterol is a free radical-mediated process resulting in numerous structural changes, all of which depend on a common initiating event, the peroxidation of polyunsaturated fatty acids in the LDL cholesterol compound (Jialal and Devaraj 1996). The inhibitory effect of conjugated diene (CD) formed after $8 \mathrm{~h}$ by barley fractions was measured in the current study and is presented in (Fig. 3). Our previous research showed that the rate of CD formation or LDL cholesterol oxidation of control sample (antioxidant free) reaches maximum slope after $8 \mathrm{~h}$ of oxidation, and following that it exhibits a steady rate up to $24 \mathrm{~h}$ (Abdel-Aal and Gamel 2008). Thus, in the current study $8 \mathrm{~h}$ was chosen for comparing the inhibitory effects of different barley fractions against the LDL oxidation and conjugated diene formation.

The inhibition of LDL oxidation by different barley wholegrain flours and pearling fractions followed the same order as that obtained in the free radicals scavenging capacity tests. The outer layer fractions had the highest reduction of conjugated dienes formation. The middle pearling fractions had a different trend as it showed high capability to reduce the $C D$ formation similar to the outer layer and it was higher than the hull fractions except for AC parkhill (Fig 3). The outer layer, middle and hull fractions were able to reduce the $C D$ formation after $8 \mathrm{~h}$ by $64-67.5 \%, 47.5-67 \%$ and $30.5-64.5 \%$, respectively. Ferulic acid and $\mathrm{BHA}$ as reference compounds were able to block the oxidation of $\mathrm{CD}$ during the incubation time. On the other hand, the inner layer fractions which are largely endosperm showed the lowest capacity to retard the LDL cholesterol oxidation. This result is in agreement with a previous study (Madhujith and Shahidi, 2007) where phenolic compounds present in whole barley cultivars were effective in scavenging free radicals and controlling oxidation of LDL cholesterol.

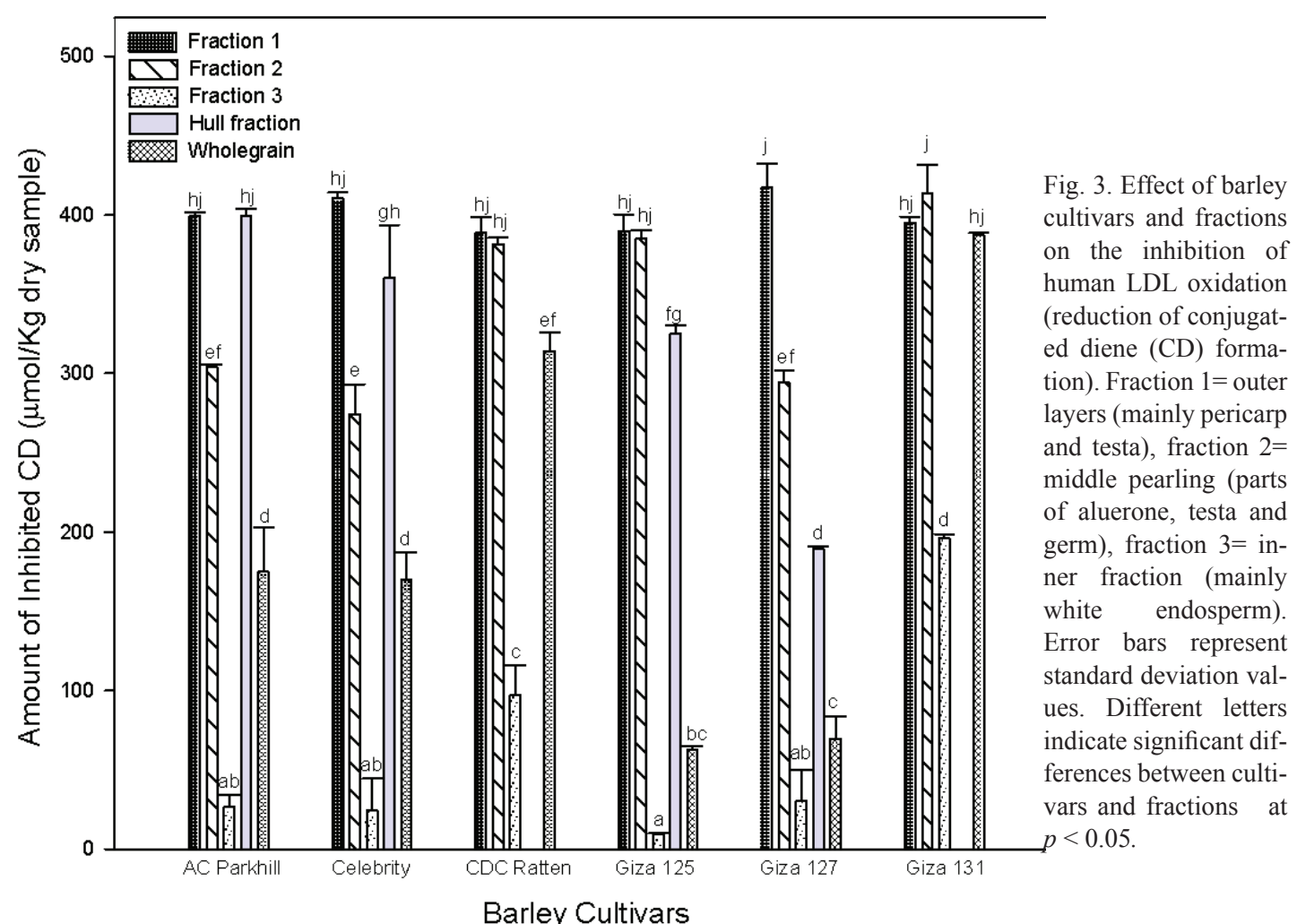




\section{AGRICULTURAL AND FOOD SCIENCE}

T. Gamel and E-S. Abdel-Aal (2012) 21: 118-131

\section{Correlation analysis}

Ferulic, $p$-coumaric, vanillic and caffeic acids comprise above $95 \%$ of the total phenolic acids found in barley. These individual phenolic acids and total phenolic acids content were correlated with DPPH, ABTS and LDL oxidation tests. Although free phenolic acids are existing in lower amounts than the bound ones (Madhujith and Shahidi 2009, Yoshida et al. 2010), they still contribute to antioxidant properties of barley grains as described previously (Madhujith et al. 2006, Mpofu et al. 2006, Madhujith and Shahidi 2007). Pearson correlation between the major selected phenolic acids and antioxidant capacities are presented in Table 4. In general positive correlations were observed between all phenolic acids and antioxidant measurements. Ferulic and vanillic acids and total phenolic acids had extremely highly significantly correlations with all the antioxidant tests $(p=0.00)$, while caffeic acid associated highly significantly with CD formation $(p=0.004)$ and extremely highly significantly with DPPH and ABTS tests $(p=0.00)$. Unexpectedly, $p$-coumaric acid exhibited insignificant correlations with the reduction in CD formation (LDL oxidation) and ABTS tests, but it had significant correlation with DPPH scavenging capacity $(p=0.04)$. This observation would warrant further investigation particularly antioxidant properties of barley were measured in aqueous methanolic extracts that contain only soluble phenolics. It was reported that $p$-coumaric acid had the least antioxidant effect among the major hydrocinnamic acids (Shahidi and Chandrasekara 2010). Although only soluble phenolics present in the methanolic extracts, the significant correlations suggest a strong role for phenolic acids as antioxidant compounds. The results also suggest that the addition of wholegrain barley or outer layer fraction in food dry mixes may boost the antioxidant properties and would help mitigate oxidative stress related disease conditions.

Table 4. Pearson correlation analysis between major phenolic acids in barley and antioxidant measurements.

\begin{tabular}{llll}
\hline & DPPH & ABTS & Conjugated diene \\
\hline Ferulic & $0.793^{\mathrm{a}}$ & 0.764 & 0.681 \\
& $0.000^{\mathrm{b}}$ & 0.000 & 0.000 \\
& & & \\
& 0.421 & 0.401 & 0.367 \\
-Coumaric & 0.040 & 0.052 & 0.077 \\
& & & \\
Vanillic & 0.753 & 0.800 & 0.636 \\
& 0.000 & 0.000 & 0.001 \\
Caffeic & 0.772 & 0.684 & 0.567 \\
& 0.000 & 0.000 & 0.004 \\
Total Phenols & 0.788 & 0.759 & 0.671 \\
& 0.000 & 0.000 & 0.000 \\
\hline
\end{tabular}

${ }^{\mathrm{a}}$ Correlation coefficient (r).

${ }^{\mathrm{b}} p$ value $(<0.05$ : significant, $<0.01$ : highly significant, $<0.001$ : very highly significant $), \mathrm{n}=24$. 


\section{AGRICULTURAL AND FOOD SCIENCE}

\section{Conclusions}

In general significant variations were observed between barley wholegrain flours and pearling/milling fractions in terms of phenolic acids composition and antioxidant capacity. The wholegrain flours obtained from the Egyptian barleys and the Canadian cultivar CDC Rattan, and the outer layer and hull fractions exhibited high contents of phenolic acids and antioxidant properties, holding a potential as functional food ingredients and/or natural antioxidants. The study also demonstrates the importance of barley wholegrain and/or the outer layer fractions as natural food antioxidants.

\section{Acknowledgment}

The authors are grateful to Cribit Seeds (West Montrose, ON, Canada), Dr. Brian Rossnagel from University of Saskatchewan (Saskatoon, SK, Canada) and the Agricultural Research Centre, Field Crop Research Institute (Giza, Egypt) for providing barley cultivars and to the Agriculture and Agri-Food Canada and the Egyptian Ministry of Higher Education for providing resources and financial support.

\section{References}

Abdel-Aal, E.-S.M. \& Gamel, T.H. 2008. Effects of selected barley cultivars and their pearling fractions on the inhibition of human LDL oxidation in vitro using a modified conjugated dienes method. Cereal Chemistry 85: $730-737$.

Abdel-Aal, E.-S.M. \& Rabalski, I. 2008. Bioactive compounds and their antioxidant capacity in selected primitive and modern wheat species. The open Agriculture Journal 2: 7-14.

Abdel-Aal, E.-S. M., Hucl, P.J., Sosulski, F.W., Graf, R.J., Gillott, C. \& Pietrzak, L.N. 2001. Screening spring wheat for midge resistance in relation to ferulic acid content. Journal of Agriculture and Food Chemistry 49: 3559-3566.

Arts, M.J.T.J., Dallinga, J.S., Voss, H.-P., Haenen, G.R.M.M. \& Bast, A. 2004. A new approach to assess the total antioxidant capacity using the TEAC assay. Food Chemistry 88: 567-570.

Behall, K.M. \& Hallfrisch, J. G. 2006. Effect of barley consumption on CVD risk factors. Cereal Foods World 51: 12-15.

Beta, T., Nam, S., Dexter, J.E. \& Sapirstein, H. D. 2005. Phenolic content and antioxidant activity of pearled wheat and roller-milled fractions. Cereal Chemistry 82: $390-393$.

Butsat, S. \& Siriamornpun, S. 2010. Antioxidant capacities and phenolic compounds of the husk, bran and endosperm of Thai rice. Food Chemistry 119: 606 -613.

Choi, Y., Jeong, H.-S. \& Lee, J. 2007. Antioxidant activity of methanolic extracts from some grains consumed in Korea. Food Chemistry 103: 130-138.

Christie, P.J., Alfenito, M.R. \& Walbot, V. 1994. Impact of low-temperature stress on general phenylpropanoid and anthocyanin pathways: enhancement of transcript abundance and anthocyanin pigmentation in maize seedlings. Planta 194: 541-549.

Cook, N.C. \& Sammon, S. 1996. Flavonoids: chemistry, metabolism, cardioprotective effects and dietary sources. Journal of Nutritional Biochemistry 7: 66-77.

Du, L., Yu, P., Rossnagel, B.G., Christensen, D.A. \& McKinnon, J.J. 2009. Physicochemical characteristics, hydroxycinnamic acids (ferulic acid, p-coumaric acid) and their ratio, and in situ biodegradability: comparison of genotypic differences among six barley varieties. Journal of Agriculture and Food Chemistry 57: 4777-4783.

Duthie, G.G., Duthie, S.J. \& Kyle, J.A.M. 2000. Plant polyphenols in cancer and heart disease: Implications as nutritional antioxidants. Nutrition Research Review 13: 79-106.

Dykes, L. \& Rooney, L.W. 2007. Phenolic compounds in cereal grains and their health benefits. Cereal Food World 52: 105-111.

Esterbauer, H., Striegl, G., Puhl, H. \& Rotheneder, M. 1989. Continuous monitoring of in vitro oxidation of human low density lipoprotein. Free Radical Research Communication 6: 67-75. 


\section{AGRICULTURAL AND FOOD SCIENCE}

T. Gamel and E-S. Abdel-Aal (2012) 21: 118-131

Frei, B. 1995. Cardiovascular disease and nutrient antioxidants: role of low-density lipoprotein oxidation. Critical Reviews in Food Science and Nutrition 35: 83-98.

Goupy, P., Hugues, M., Boivin, P. \& Amiot, M.J. 1999. Antioxidant composition and activity of barley (Hordeum vulgarae) and malt extracts of isolated phenolic compounds. Journal of the Science of Food and Agriculture 79: 1625-1634.

Hernanz, D., Nuńez, V., Sancho, A.I., Faulds, C.B., Williamson, G., Bartolomé, B. \& Gómez-Cordovés, C. 2001. Hydroxycinnamic acids and ferulic acid dehydrodimers in barley and processed barley. Journal of Agriculture and Food Chemistry 49: 4884-4888.

Jadhav, S.J., Lutz, S.E., Ghorpade, V.M. \& Salunkhe, D.K. 1998. Barley: Chemistry and value-added processing. Critical Reviews in Food Science and Nutrition 38: 123-171.

Jialal, I. \& Devaraj, S. 1996. Low-density lipoprotein oxidation, antioxidants, and atherosclerosis: a clinical biochemistry perspective. Clinical Chemistry 42: 498-506.

Kim, H., Behall, K.M., Vinyard, B. \& Conway, J.M. 2006. Short-Term satiety and glycemic response after consumption of whole grains with various amounts of $\beta$-glucan. Cereal Foods World 51: 29-33.

Kim, M.-J., Hyun, J.-N., Park, J.-C., Kim, J.-G., Lee, S.-J., Chun, S.-C. \& Chung, I.-M. 2007. Relation between phenolic compounds, anthocyanins content and antioxidant activity in colored barley germplasm. Journal of Agriculture and Food Chemistry 55: 4802-4809.

Klepacka, J. \& Fornal, L. 2006. Ferulic acid and its position among the phenolic compounds of wheat. Critical Reviews in Food Science and Nutrition 46: 639-647.

MacGregor, A. W. \& Fincher, G. B. 1993. Carbohydrate of the barley grain. In MacGregor, A.W. \& Bhatty, R.S. (eds.). Barley: Chemistry and Technology. St. Paul, MN: AACC International. P. 73-130.

Madhujith, T. \& Shahidi, F. 2007. Antioxidative and antiproliferative properties of selected barley (Hordeum vulgarae L.) cultivars and their potential for inhibition of low-density lipoprotein (LDL) cholesterol. Journal of Agriculture and Food Chemistry 55: 5018-5024.

Madhujith, T. \& Shahidi, F. 2009. Antioxidant potential of barley as affected by alkaline hydrolysis and release of insoluble-bound phenolics. Food Chemistry 117: 615-620.

Madhujith,T., Izydorczyk, M. \& Shahidi, F. 2006. Antioxidant properties of pearled barley fractions. Journal of Agriculture and Food Chemistry 54: 3283-3289.

Maillard, M.N. \& Berset, C. 1995. Evolution of antioxidant activity during kilning: Role of insoluble bound phenolic acids of barley and malt. Journal of Agriculture and Food Chemistry 43: 1789-1793.

Manach, C., Scalbert, A., Morand, C., Rémésy, C. \& Jiménez, L. 2004. Polyphenols: Food sources and bioavailability. American Journal of Clinical Nutrition 79: 727-747.

McMurrough, I. \& Madigan, D. 1996. Semipreparative chromatographic procedure for the isolation of dimeric and trimeric proanthocyanidins from barley. Journal of Agriculture and Food Chemistry 44: 1731-173.

Mpofu, A., Sapirstein, H.D. \& Beta, T. 2006. Genotype and environmental variation in phenolic content, phenolic acid composition, and antioxidant activity of hard spring wheat. Journal of Agriculture and Food Chemistry 54: 1265-1270.

Mussatto, S.I., Dragone, G. \& Roberto, I.C. 2007. Ferulic and p-coumaric acids extraction by alkaline hydrolysis of brewer's spent grain. Industrial Crops and Products 25: 231-237.

Nogués, S., Allen, D.J., Morison, J.I.L. \& Baker, N.R. 1998. Ultraviolet-B radiation effects of water relations. Leaf development and photosynthesis in droughted pea plants. Plant Physiology 117: 173-181.

Peterson, D.M. 1994. Barley tocols: effect of milling, malting and mashing. Cereal Chemistry 71: 42-44.

Pins, J.J. \& Kaur, H. 2006. A review of the effects of barley $\beta$-glucan on cardiovascular and diabetics risk. Cereal Foods World 51: 8-11.

Qingming, Y., Xianhui, P., Weibao, K., Hong, Y., Yidan, S., Li, Z., Yanan, Z., Yuling, Y., Lan, D. \& Guoan, L. 2010. Antioxidant activities of malt extract from barley (Hordeum vulgare L.) toward various oxidative stress in vitro and in vivo. Food Chemistry 118: 84-89.

Ragaee, S., Abdel-Aal, E.-S. M. \& Noaman., M. 2006. Antioxidant activity and nutrient composition of selected cereals for food use. Food Chemistry 98: 32-38.

Shahidi, F., \& Chandrasekara, A. 2010. Hydroxycinnamates and their in vitro and in vivo antioxidant activities. Phytochemistry Reviews 9: 147-170. 


\section{AGRICULTURAL AND FOOD SCIENCE}

T. Gamel and E-S. Abdel-Aal (2012) 21: 118-131

Szwajgier, D., Pielecki, J. \& Targonski, Z. 2005. Changes of free ferulic and coumaric acid contents during malting of barley grain. Polish Journal of Food and Nutrition Science 14: 423-429.

Terpinc, P. \& Abramovič, H. 2010. A kinetic approach for evaluation of the antioxidant activity of selected phenolic acids. Food Chemistry 121: 366-371.

Trombino, S., Serini, S., Di Nicuolo, F., Celleno, L., Andò, S., Picci, N., Calviello, G. \& Palozza, P. 2004. Antioxidant effect of ferulic acid in isolated membranes and intact cells. Journal of Agriculture and Food Chemistry 52: $2411-2420$.

Wolever, T.M.S. 2006. Glycemic index and disease. In: Wolever, T. M. S. (ed.). The glycemic index: A physiological classification of dietary carbohydrate. Oxford, UK: CABI publishing. p. 164-174.

Wood, P.J. 2007. Cereal $\beta$-glucans in diet and health. Journal of Cereal Science 46: 230-238.

Yokoyama, W.H. 2006. Soluble fibers prevent insulin resistance in hamsters fed high saturated fat diets. Cereal Foods World 50: 16-18.

Yoshida, A., Sonoda, K., Ogata, Y., Nagamine, T. Sato, T., Oki, T., Hashimoto, N.S. \& Ohta, H. 2010. Determination of free and bound phenolic acids, and evaluation of antioxidant activities and total polyphenolic contents in selected pearled barley. Food Science and Technology Research 16: 215-224.

Zielinski, H. 2002. Low molecular weight antioxidants in the cereal grain: A review. Polish Journal of Food and Nutrition Science 11: 3-9. 